\title{
Integrative veterinary medical education and consensus guidelines for an integrative veterinary medicine curriculum within veterinary colleges
}

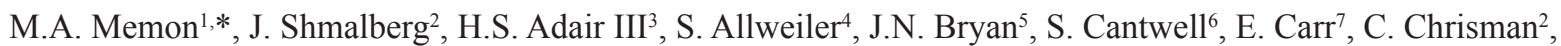
C.M. Egger ${ }^{3}$, S. Greene ${ }^{1}$, K.K. Haussler ${ }^{4}$, B. Hershey ${ }^{8}$, G.R. Holyoak ${ }^{9}$, M. Johnson ${ }^{2}$, S. Le Jeune ${ }^{10}$, A. Looney ${ }^{11}$, R.S. McConnico ${ }^{12}$, C. Medina ${ }^{13}$, A.J. Morton ${ }^{2}$, A. Munsterman ${ }^{14}$, G.J. Nie ${ }^{15}$, N. Park ${ }^{16}$, M. Parsons-Doherty ${ }^{17}$, J.A. Perdrizet ${ }^{18}$, J.L. Peyton ${ }^{10}$, D. Raditic ${ }^{19}$, H.P. Ramirez ${ }^{2}$, J. Saik ${ }^{20}$, S. Robertson ${ }^{7}$, M. Sleeper ${ }^{2}$, J. Van Dyke ${ }^{21}$ and J. Wakshlag 22

${ }^{1}$ Department of Clinical Science, College of Veterinary Medicine, Washington State University, Pullman, WA, USA ${ }^{2}$ Departments of Small Animal Clinical Sciences (Shmalberg, Chrisman, Johnson, Sleeper), Large Animal Clinical Sciences (Morton), and Biomedical Sciences (Ramirez), College of Veterinary Medicine, University of Florida, Gainesville, FL, USA

${ }^{3}$ Department of Small Animal Clinical Sciences (Egger) and Department of Large Animal Clinical Sciences (Adair), College of Veterinary Medicine, University of Tennessee, Knoxville, TN, USA

${ }^{4}$ Department of Clinical Sciences, College of Veterinary Medicine and Biomedical Sciences, Colorado State University, Fort Collins, CO, USA

${ }^{5}$ Department of Veterinary Medicine and Surgery, College of Veterinary Medicine, University of Missouri, Columbia, MO, USA

${ }^{6}$ Medicine Wheel Veterinary Services, Ocala, FL, USA

${ }^{7}$ Department of Small Animal Clinical Sciences (Robertson) and Department of Large Animal Clinical Sciences (Carr), College of Veterinary Medicine, Michigan State University, East Lansing, MI, USA

${ }^{8}$ Integrative Veterinary Oncology, Phoenix, AZ, USA

${ }^{9}$ Department of Veterinary Clinical Sciences, Center for Veterinary Health Sciences, Oklahoma State University, Stillwater, OK, USA

${ }^{10}$ Veterinary Medical Teaching Hospital (Peyton) and Department of Surgical and Radiological Sciences (Le Jeune), School of Veterinary Medicine, University of California, Davis, CA, USA

${ }^{11} I V G$ Hospitals, Woburn, MA, USA

${ }^{12}$ Department of Veterinary Clinical Sciences, Louisiana State University, Baton Rouge, LA, USA

${ }^{13}$ Coral Springs Animal Hospital, Coral Springs, FL, USA

${ }^{14}$ Department of Clinical Sciences, College of Veterinary Medicine, Auburn University, Auburn, Alabama, USA

${ }^{15}$ Angel Animal Hospital, Springfield, MO, USA

${ }^{16}$ Integrative Ophthalmology for Pets, Los Angeles, CA, USA

${ }^{17}$ North Houston Veterinary Specialists, Spring, TX, USA

${ }^{18}$ The Sanctuary Animal Clinic, Holyoke, MA, USA

${ }^{19}$ Independent, USA

${ }^{20}$ Winterville Animal Clinic, Winterville, GA, USA

${ }^{21}$ Canine Rehabilitation Institute, Wellington, FL, USA

${ }^{22}$ Department of Clinical Sciences, College of Veterinary Medicine, Cornell University, Ithaca, NY, USA

\begin{abstract}
Integrative veterinary medicine (IVM) describes the combination of complementary and alternative therapies with conventional care and is guided by the best available evidence. Veterinarians frequently encounter questions about complementary and alternative veterinary medicine (CAVM) in practice, and the general public has demonstrated increased interest in these areas for both human and animal health. Consequently, veterinary students should receive adequate exposure to the principles, theories, and current knowledge supporting or refuting such techniques. A proposed curriculum guideline would broadly introduce students to the objective evaluation of new veterinary treatments while increasing their preparation for responding to questions about IVM in clinical practice. Such a course should be evidence-based, unbiased, and unaffiliated with any particular CAVM advocacy or training group. All IVM courses require routine updating as new information becomes available. Controversies regarding IVM and CAVM must be addressed within the course and throughout the entire curriculum. Instructional honesty regarding the uncertainties in this emerging field is critical. Increased training of future veterinary professionals in IVM may produce an openness to new ideas that characterizes the scientific method and a willingness to pursue and incorporate evidence-based
\end{abstract}


medicine in clinical practice with all therapies, including those presently regarded as integrative, complementary, or alternative.

Keywords: Complementary and alternative veterinary medicine, Integrative veterinary course, Integrative veterinary curriculum, Integrative veterinary medicine, Veterinary education.

\section{Introduction}

Veterinarians frequently encounter questions about complementary and alternative veterinary medicine $(\mathrm{CAVM})$ in practice, and the general public has demonstrated increased interest in these areas for both human and animal health (Lana et al., 2006; Frass et al., 2012; Harris et al., 2012). An American Veterinary Medical Association (AVMA) resolution established that the organization "recognizes the interest in and use of these modalities and is open to their consideration" (AVMA Alternative and Complementary Therapies Task Force, 2001). The exact prevalence of CAVM has not been quantified in veterinary medical practice, but more than one-third of the general human population has used such techniques for their own health (Frass et al., 2012; Harris et al., 2012). In addition, a large number of owners presenting their animals to a veterinary oncology clinic reported using CAVM therapies for their pets, and often without the knowledge or supervision of a veterinarian (Lana et al., 2006).

Alternative and complementary veterinary medicine is defined by the AVMA as a "heterogeneous group of preventive, diagnostic, and therapeutic philosophies and practices" which may "diverge from veterinary medicine routinely taught in North American veterinary medical schools or may differ from current scientific knowledge, or both" (AVMA Alternative and Complementary Therapies Task Force, 2001). The National Institutes of Health (NIH) center dedicated to similar techniques for human medicine defines complementary medicine as "non-mainstream" practice when combined with conventional medicine, and alternative medicine when the same interventions are used in place of conventional medicine. The AVMA provides a list of CAVM modalities, which includes photon therapy (laser), acupuncture, homeopathy, veterinary manipulative therapy, nutraceutical therapy and phytotherapy among others.

Integrative veterinary medicine (IVM) best encapsulates the consensus goals of a training and experiential education model in CAVM. Integrative medicine has been described as the combination of complementary and alternative therapies with conventional care, and is guided by the best available evidence (Kligler et al., 2004). The growing preference for this terminology is exemplified by the renaming of the NIH National Center for Complementary and Alternative Medicine's (NCCAM) to the National Center for Complementary and Integrative Health (NCCIH, nccih.nih.gov). The strategic plan for the $\mathrm{NCCIH}$ stresses the development and dissemination of objective, evidence-based information on CAM interventions, with professional education as a pillar (Health, 2011). The authors of this consensus guideline agree that the veterinary profession should similarly position graduates of AVMA-accredited colleges to respond to the growing interest in this field using an evidence-based approach. IVM is currently practiced in both veterinary colleges and in private practices (Shmalberg and Memon, 2015). A number of private certification programs provide training in many of the techniques described by integrative medicine, but neither the AVMA nor any other regulatory body supervises the type of training participants receive. Adefinition of integrative medicine similar to the one employed by human medical colleges and physicians is presented in this manuscript.

The need for clear consensus guidelines is supported by a 2011 survey of AVMA-accredited colleges on the status of CAVM training programs for veterinary students (Memon and Sprunger, 2011). The survey respondents indicated that students should be aware of CAVM modalities because of the strong public interest in CAVM and because practitioners should be able to address client questions from a position of knowledge. Nearly $25 \%$ percent of recent Washington State University graduates reported facing questions about CAVM on a weekly or daily basis, and veterinary students polled had a positive outlook towards CAVM education (Memon and Sprunger, 2011). These findings prompted the formation of a national curriculum committee supported by the American Academy of Veterinary Acupuncture (AAVA) tasked with developing a model curriculum for veterinary students. Available committee members met during the AAVA annual conference in New Orleans during May 2013, at which time those present agreed that IVM should be the focus and title of a model training course. The course outline was discussed, and consensus established that the following IVM modalities commonly used in veterinary practices should be included in the curriculum: acupuncture, veterinary manipulative therapy, integrative nutrition, physical rehabilitation and sports medicine and herbal therapy.

\section{Current curricular trends \\ Integrative medical training in human health professions}

The National Center for Complementary and Alternative Medicine (NCCAM) awarded grants to 12 medical schools, two nursing schools, and one foundation for 
development of a Complementary and Alternative Medicine (CAM) curriculum in 2001. All 15 NCCAMfunded institutions developed similar CAM curricula with three "Guiding Principles" of foundational skills, evidence-based analysis, and lifelong learning techniques (Gaster et al., 2007). Foundational skills were taught as an introduction to the principles of CAM before individual modalities were taught. Introductory concepts were designed to impart an understanding of the terminology of CAM, integrative medicine, and the basic principles of non-conventional medical philosophies, such as traditional Chinese medicine. Evidence-based analysis was encouraged with the following questions: 1 . Is there significant scientific evidence for a therapy's efficacy or harm? 2. Is there evidence that a therapy is being widely used by patients? and 3. Does a therapy have the potential to treat a medical condition for which conventional medical approaches are lacking? These questions were also the basis for determining what modalities were discussed. For example, at least one criterion had to be satisfied for inclusion in the proposed CAM curriculum, and considerable deference was given to the presentation of evidence and safety of the included CAM modalities. The curriculum guidelines recommended Tools for the Future, or the stated goal that students develop longlasting tools for self-learning about CAM.

The NCCAM-funded educational initiative led schools to design CAM curricula that fostered an openminded, evidence-based approach to patient care while recognizing the deficits and challenges in clinical research for CAM interventions. Surveys of CAM education in human health training programs continue to demonstrate an expansion of CAM training and the emergence of different CAM curriculum designs (Benjamin et al., 2007; Frenkel et al., 2007; Marcus and McCullough, 2009).

\section{Critiques of human health professions training in CAM}

Several fundamental challenges to CAM training in human medical training programs have been raised, and these are largely reflective of the perceived evidence or lack thereof for many of the modalities selected for the curriculum (Marcus and McCullough, 2009). Some opponents raised concern that the inclusion of these techniques violated the evidence-based foundational principles of medical education. The amount of evidence for many of these various interventions is unknown, but Ernst (2011) has proposed that 7.3\% of CAM techniques have supportive evidence justifying their use in contrast to $25-75 \%$ of conventional techniques. Other educators cite the fundamental assumptions of some systems, such as homeopathy, which are divergent from conventional approaches. Errors in reasoning and cognitive bias are also raised, as is the natural course of chronic disease in which there is a cyclical regression to the mean, or periods of expected partial improvement after a patient presents with severe clinical signs. The placebo effect has been thoroughly described in humans, and there is significant debate as to whether CAM interventions that provide positive placebo responses are warranted if they do improve patient outcome.

\section{Current IVM courses in AVMA-accredited colleges}

The survey of the AVMA-accredited veterinary institutions reported that $16(47 \%)$ out of 34 respondent colleges offered a CAVM course (Memon and Sprunger, 2011). Acupuncture, chiropractic, physical rehabilitation, integrative nutrition, herbal therapy, and homeopathy were the most common topics included in the curricula. One college reported having a required course in CAVM, whereas all other courses were elective. Most of the courses were 1-2 credit hours. The majority included a combination of lecture and laboratory, whereas 2 were lecture only and 1 was laboratory only. The 18 colleges without any course in CAVM or IVM reportedly addressed these topics in other courses, and 4 indicated plans to offer a dedicated CAVM course within the next 5 years.

The information in the previously published survey is now outdated, as demonstrated by currentlytaught CAVM curriculum at several institutions. The University of Florida modified its course four years ago to include an IVM focus, with an emphasis on the integration of CAVM with conventional veterinary care and which is based on an assessment of the evidence for the different complementary interventions. Washington State University has included invited speakers in its CAVM course to expand its training in this area. Louisiana State University has recently hired a faculty member to offer clinical services and teaching in CAVM, and the University of California-Davis expanded a rehabilitation service to include integrative medicine. Colorado State University continues to provide training in CAVM and has been involved with medical acupuncture initiatives. Faculty members at a number of other accredited institutions without dedicated clinical programs have obtained training in this area, and many are authors of this consensus guideline.

\section{Critiques of CAVM or IVM}

The call for veterinary medical education in these core IVM areas is often met with similar arguments as to those presented to training institutions in the human health professions (Marcus, 2001; Marcus and McCullough, 2009; McKenzie, 2012). The AVMA statement on CAVM states that the "quality of studies and reports pertaining to CAVM varies; therefore, it is incumbent on a veterinarian to critically evaluate the literature and the other sources of information" (AVMA Alternative and Complementary Therapies Task Force, 2001). The academic administrators surveyed by Memon and Sprunger frequently responded that CAVM 
must be taught using sound evidence-based medicine (Memon and Sprunger, 2011). These comments are similar to those of other authors who maintain that all veterinary medicine should use the same standards of evaluation and be guided by evidence rather than clinical impression (McKenzie, 2012). The placebo effects of some treatments, through either the owner's response to therapy or the animal's, should also be considered. A placebo effect has been documented in animals receiving therapeutic interventions, and it should be recognized that some CAVM as well as conventional therapies may well exert clinical effects based on such mechanisms (McMillan, 1999; Muñana et al., 2010).

\section{Consensus response to CAVM and IVM critiques}

The authors agree that evidence-based principles should be uniformly applied across the curriculum. However, comprehensive reviews of evidence-based medicine (EBM) demonstrate challenges in other areas of the accepted veterinary curricula and clinical practice (Vandeweerd et al., 2012). Therefore, all interventions, whether complementary or conventional, should be uniformly assessed, and students should be given the educational skills for such evaluation, which is consistent with the opinions of previous critiques (McKenzie, 2012). Comprehensive reviews of the EBM approach are provided elsewhere and beyond the scope of these guidelines (Holmes, 2009). A course in IVM could serve as a model for the EBM approach by allowing students to consider a variety of sources, such as lecture, laboratory training, expert opinion, and published research, to derive their own conclusions. The University of Florida presently adopts such a model and students submit an evaluation of an IVM intervention to demonstrate competency in this approach. Irrespective of the merits of a particular modality, exposure to the tenets of such a system allows graduating veterinarians to better communicate with clients on these topics. Recent graduates frequently stress the importance of the their relationship with clients, and the authors hypothesize that a working understanding of IVM better positions practitioners to provide guidance on owner requests to use CAVM (Rhind et al., 2011).

Divergent medical systems, such as Traditional Chinese Veterinary Medicine (TCVM) and homeopathy, should be presented inclusive of their underlying philosophical principles and controversies surrounding what may be perceived as dogmatic or experiential medicine should be addressed (Marcus and McCullough, 2009). The historical origins of veterinary acupuncture, for example, have been highly debated in the literature, while other authors stress the importance of foundational principles in treatment (Imrie et al., 2001; Ramey and Buell, 2004; Xie and Preast, 2013). However, the evidence of the modernity of veterinary acupuncture as commonly practiced can be presented, and students can determine the utility of traditional healing systems (Shmalberg, 2014a). Similarly, homeopathic principles can be presented along with systematic analysis of its use in veterinary medicine (Mathie and Clausen, 2015).

Barriers to an expansion of IVM training in veterinary curricula

The most common barriers cited by respondents to Memon and Sprunger's survey were related to limited teaching budgets, the lack of time in the current curriculum, the unavailability of qualified CAVM faculty or instructors whom would follow an EBM approach, or insufficient support from a college's administration (Memon and Sprunger, 2011). Respondents from some of the colleges teaching CAVM courses mentioned the criticisms of CAVM modalities as another barrier. The logistical barriers might be less onerous with the development of a model course, such as that suggested herein. Many of the committee members support distance or online education in this field when resources are limited. IVM faculty teaching within an established IVM training program is often available to assist other programs in the development of an educational model.

\section{Goals and justifications for a standard IVM course}

The fundamental goal of an IVM course should be to provide unbiased exposure to CAVM modalities and to discuss their integration into the broader conventional veterinary medical framework. The course should strongly emphasize both positive and negative viewpoints and evidence surrounding the particular modalities, and it should be structured in such a way that students are challenged to make their own assessments of the suitability of techniques to different patient populations. The primary areas of instruction are those that the students are most likely to encounter in clinical practice. A recent retrospective study of an academic IVM service found that acupuncture, physical rehabilitation, and hydrotherapy were the modalities most frequently administered to a patient population that suffered primarily from orthopedic and neurologic diseases (Shmalberg and Memon, 2015). The established IVM curriculum at many veterinary colleges provides instruction in acupuncture, veterinary manipulative therapy, physical rehabilitation, botanical or herbal medicine, and integrative nutrition (Memon and Sprunger, 2011). Divergent medical theories of TCVM and homeopathy should be presented for reference information.

\section{Course goals}

1. Recognize the different complementary treatment modalities that are available to veterinary patients and the reasons why owners are increasingly interested in such therapies.

2. Understand the evidence-based application of IVM techniques in combination with conventional care.

3. Understand the benefits and limitations of 
complementary medical systems including acupuncture, veterinary manipulative therapy, physical rehabilitation, integrative nutrition, and botanical medicine.

4. Describe the common orthopedic and neurologic injuries in pets and performance animals and understand the benefits and limitations of complementary techniques for these conditions.

5. Evaluate novel trends in animal diets using evidence-based clinical nutrition.

6. Understand the approaches of alternative medical systems such as TCVM and homeopathy.

7. Research and communicate the advantages, disadvantages, and evidence for a CAVM modality as opposed to, or in combination with, a conventional approach (course project).

Student learning should be evaluated using appropriate educational assessment tools (Rhind et al., 2008). A project in which students assimilate and expand on course information is likely well suited to verifying the success of an EBM approach to IVM education. Specific outcome assessments may need to be developed to assess veterinary student knowledge of integrative medicine vocabulary, core concepts, and clinical application before, immediately after, and after an extended period to evaluate the efficacy of the course.

A pre- and post-course survey would provide information as to the perceived benefits and limitations of such a course. An extended survey to include postgraduate assessments of the course's value would provide even more valuable feedback. The course should be updated to reflect the responses of current and past students and newly emerging evidence.

\section{Proposed course structure}

The following proposed one semester credit course could be offered within any clinical academic department during the veterinary curriculum. However, it would ideally be placed following students obtaining core knowledge of orthopedic, neurologic, and evidence-based medicine, likely during the junior year. A course catalog description could include the following proposed language:

"This course introduces critical concepts and modalities of IVM, with an emphasis on the integration of evidencebased complementary medical techniques. Students will learn to evaluate integrative medical interventions in the context of conventional care and to determine if such modalities could improve patient outcomes for management of disease processes. Students should also expect to develop an improved ability to discuss such therapies with peers and clients".

This course may be offered as an elective, but the authors view the course as an emerging part of a refined core veterinary curriculum. It is a necessary introduction to concepts that are required when graduates pursue future study in IVM and when practicing clinicians are confronted with clients' questions about these techniques.

The authors propose a model IVM course to serve as a minimal standard for veterinary student training in this area (Table 1).

\section{Justification for proposed course topics}

Students should be aware at the outset of the course of the fundamental debates surrounding integrative education in a biomedical context (Marcus and McCullough, 2009; Sierpina and Kreitzer, 2010). The meanings assigned to integrative, complementary, holistic, alternative, conventional, and allopathic medicine by both the general public and veterinary professionals will help to inform the context of many of the modalities to be discussed. The evidence-based medicine evaluation system and grades of evidence provide students with an evaluation tool for all facets of medicine (Evans, 2009; Holmes, 2009). The unique challenges of evidence-based medicine across the veterinary profession should be discussed, and the current understanding of human and animal placebo reviewed (McMillan, 1999; Vandeweerd et al., 2012). The latter raises broader questions about the response of a disease to a treatment and why interventions may work when they in fact exerted no measurable or known effect. These reasons have been explored extensively elsewhere but include temporal changes in a disease, a regression to the mean, the effect of non-treatment influences, confirmation bias, cognitive dissonance, and owner outlook (Hartman, 2009). The controversial aspects of homeopathy and TCVM can be discussed in such a context, given that some authors suggest such interventions are "implausible on a priori grounds" lack scientifically acceptable rationale, have insufficient supporting evidence, have failed in clinical trials, and seem improbably on common sense grounds (Beyerstein, 2001). The course faculty should be respectful, regardless of personal opinions or assessments, in understanding that this proposed course exists within the confines of conventional allopathic training. Personal bias, positive or negative, should not influence the nature of instruction. Finally, case scenarios should be used to demonstrate the possible interactions of therapies and the complicated nature of integrative medicine, which by definition may include the effects of accepted treatments and other modalities.

\section{Veterinary acupuncture}

Acupuncture, or needle stimulation of various points on the body, generally relies on an understanding of neuroanatomic and musculoskeletal structures. Consequently, the current proposed physiologic effects of acupuncture should be presented with the most recent literature on possible mechanisms (Ulett et al., 1998; Cantwell, 2010; Zhang et al., 2014). These include direct neural stimulation, cannabinoid 
Table 1. Outline of a model integrative veterinary medicine course for veterinary students.

\begin{tabular}{|c|c|c|c|}
\hline Course topic & Lecture hours & Lab hours & Main sub-topics \\
\hline $\begin{array}{l}\text { Basic } \\
\text { concepts }\end{array}$ & 3 & 0 & $\begin{array}{l}\text { (1) Integrative veterinary medicine: History, definitions, and context } \\
\text { (2) Applications of evidence-based medicine to IVM and current controversies } \\
\text { (TCVM, homeopathy, placebo) } \\
\text { (3) Multi-modality treatments and integration of complementary therapies with } \\
\text { conventional therapy }\end{array}$ \\
\hline Acupuncture & 3 & 2 & $\begin{array}{l}\text { (1) Anatomy and physiology of acupuncture with relation to soft tissue and } \\
\text { neurologic concepts } \\
\text { (2) Traditional theories of acupuncture: An assessment of the validity and } \\
\text { current controversies } \\
\text { (3) Integrative acupuncture: clinical approaches and current scientific literature } \\
\text { Laboratory: Proposed location of acupuncture points in the canine/or equine } \\
\text { with a discussion of the controversies in point placement and naming }\end{array}$ \\
\hline $\begin{array}{l}\text { Manual } \\
\text { therapies }\end{array}$ & 2 & 1 & $\begin{array}{l}\text { (1) Veterinary manipulative therapy: Neurology, biomechanics, and available } \\
\text { evidence } \\
\text { (2) Massage therapy and myofascial principles } \\
\text { Laboratory: Palpation laboratory and demonstration of techniques }\end{array}$ \\
\hline $\begin{array}{l}\text { Botanical } \\
\text { medicine }\end{array}$ & 2 & 0 & $\begin{array}{l}\text { (1) Origins and major systems of herbal therapy with selected evidence-based } \\
\text { interventions } \\
\text { (2) Adverse events, herb-drug interactions, supplement evaluation and regulation }\end{array}$ \\
\hline $\begin{array}{l}\text { Integrative } \\
\text { nutrition }\end{array}$ & 2 & 0 & $\begin{array}{l}\text { (1) Novel trends in nutrition: Raw diets, home-prepared diets, grain-free diets, } \\
\text { owner perceptions and current marketing } \\
\text { (2) Nutrition in select conditions: Obesity, performance, physical rehabilitation, } \\
\text { and integrative medical approaches }\end{array}$ \\
\hline $\begin{array}{l}\text { Physical } \\
\text { rehabilitation }\end{array}$ & 3 & 2 & $\begin{array}{l}\text { (1) Functional anatomy in physical rehabilitation and sports medicine with an } \\
\text { emphasis on relevant orthopedic and neurologic pathology } \\
\text { (2) Rehabilitative assessment and interventions } \\
\text { (3) Photobiomodulation (laser), shockwave, ultrasound, hyperbaric oxygen, and } \\
\text { other rehabilitative modalities } \\
\text { Laboratory: Demonstration of canine/equine physical rehabilitation techniques } \\
\text { and use of selected therapeutic modalities }\end{array}$ \\
\hline Total hours & 15 & 5 & \\
\hline
\end{tabular}

receptor activation, modulation of substance $\mathrm{P}$, release of endogenous opioids, selective activation of nerve fibers, and effects on acetylcholine. The discussion of these possible mechanisms allows for a concurrent review of the importance of such processes in conventional biomedicine and pharmacology. Acupuncture intervention can be compared with the mechanism of important analgesic drugs.

Veterinary acupuncture remains more homogenous than the many systems of human acupuncture, but controversies over point location persist, as do debates surrounding the importance of historical Chinese or Asian philosophies to the treatment protocols (Ramey, 2000; Ramey et al., 2001; Robinson, 2006; Shmalberg, $2014 b$ ). Traditional theories of acupuncture should be presented with an emphasis on providing student exposure rather than promoting any specific doctrinebased method of needle stimulation. The increasing popularity of TCVM alone justifies student familiarity with the concept, especially given that the diagnostic language future clinicians may encounter from owners or other practitioners will be different from that to which they are accustomed. The modern application of acupuncture to dogs and cats must be emphasized given that these species were historically of low economic and cultural importance in China and therefore rarely, if ever, treated with acupuncture before Western interest in the subject (Shmalberg, 2014b).

The scientific evidence for acupuncture and for specific acupoints should be presented. Habacher et al. (2006) concluded that there was no convincing evidence supporting the efficacy of veterinary acupuncture. Subsequent studies identified mixed results; dogs treated for some musculoskeletal conditions experienced no effects, whereas acupuncture for intervertebral disc disease, vomiting, and post-operative analgesia was more promising (Kapatkin et al., 2006; Hayashi et al., 2007; Joaquim et al., 2010; Groppetti et al., 2011; Koh et al., 2014; Shmalberg and Burgess, 2014). These mixed results are consistent with findings in human meta-analyses (Ernst, 2006). Study design and standardization difficulties should be reviewed in the context of current acupuncture research (Walji and Boon, 2006). 


\section{Manual therapies}

Manual therapy is broadly defined to include veterinary manipulative therapy, massage, touch, osteopathy, and related techniques. There is a paucity of data supporting such interventions, and in veterinary medicine evidence remains largely limited to equine practice (Haussler, 2009). A recent survey of equine practitioners found a generally positive view of such techniques, and over half referred owners for either veterinary chiropractic (manipulative therapy) or massage (Bergenstrahle and Nielsen, 2015). The reason for such support among equine practitioners is not clear, but could be related to an understanding of the importance of soft tissue pathology or due to the restrictions on some drug therapies in performance horses. The underlying theories of veterinary manipulative therapy involve an induced displacement of tissue, which is thought to create biologic responses influencing cells, tissue, and higher cognitive centers. The foundational basis and recommended treatments rely heavily on laboratory animal and human studies (Corti, 2014). Selective stimuli could influence chronic nociceptive inputs and affect mechanoreceptors, such as Golgi tendon apparatus and muscle spindles (Haussler, 2009). Manual therapy and acupuncture in dogs resulted in reduced muscular pain (Lane and Hill, 2016). Studies in horses suggest increased tolerance to pressure and improved vertebral flexibility following spinal manipulative therapy (Haussler et al., 2007; Sullivan et al., 2008). Massage of equine hind limb muscles increased active and passive protraction (Hill and Crook, 2010). A discussion of manual therapies provides the opportunity to discuss common sports medicine injuries in the working dog and horse as well as a review of muscle physiology and pathology.

\section{Botanical and herbal medicine}

Veterinarians and owners increasingly employ herbal supplements, and the use of such products appears most prevalent in veterinary oncology (Lana et al., 2006; Raditic and Bartges, 2014; Shmalberg and Memon, 2015). Various traditional systems of medicine incorporate natural products into medical treatments, including Chinese, Western, Ayurvedic, and indigenous North American medicine. Plant products provide potential for drug discovery, and extracts of Coriolus mushroom products and a Chinese herbal product, for example, appear promising in preliminary oncologic studies (Brown and Reetz, 2012; Wirth et al., 2014). Ursodiol, although traditionally derived from bear bile and now fortunately synthesized, was a discovery of Chinese medicine (Streeter and Wakshlag, 2015). A Chinese herbal researcher recently received a shared Nobel Prize in medicine for the discovery of the Artemisia derivatives now used to treat resistant malarial infections in humans (van der Kooy and Sullivan, 2013; Owens, 2015). Silymarin, a derivative of milk thistle, is commonly prescribed by veterinarians for hepatic diseases even in the absence of robust clinical trials (Filburn et al., 2007; Streeter and Wakshlag, 2015). Multiple publications describe hundreds of herbs and herbal combinations for use in animals with data derived from low-grade evidence including case reports, clinical experience, expert opinion or data from other species (Xie and Preast, 2004; Wynn and Fougere, 2006). Students should learn to critically evaluate botanical products and to assess the safety and ethical sourcing of such products in clinical practice.

The general public often regards herbal medications and natural products as inherently safer than standardized pharmacologic drugs (Vožeh, 2003). However, veterinarians and veterinary students should evaluate the benefits of botanical medicine in the context of possible risks. Herbal products and other dietary supplements for animals must either be a supplement generally regarded as safe (GRAS) by the Association of American Feed Control Officials or be an approved drug (Grassie, 2002). Few veterinary products meet such regulatory definitions and therefore exist in an area of regulatory uncertainty but also of low regulatory priority.

Acceptance of a therapeutic potential for botanical products implies acknowledgement that side effects could also occur. The adverse events from herbal products generally can be grouped into one of four categories: idiosyncratic or unpredictable reactions, inappropriate dose or application, inappropriate processing or misidentification, and inadvertent or intentional contamination (Shmalberg, 2014a). Recent studies have documented the presence of measurable, but non-toxic, potential contaminant metals in Chinese herbal products used in veterinary medicine as well as neuroexcitatory compounds such as strychnine (Shmalberg et al., 2013; Shmalberg, 2015). Many veterinary herbal products contain licorice root, which acts on the renal tubular cells to produce dose-dependent pseudohyperaldosteronism, the clinical effects of which have been incidentally reported in a dog (Jarrett et al., 2005; Makino et al., 2012). Severe consequences have been reported in humans administered the incorrect herbal product, including cases of urinary tract neoplasia and renal failure (Debelle et al., 2008). Therefore, veterinary students should receive adequate training in both the potential benefits and adverse events from botanical products in order to better evaluate the increasingly frequent inquiries from owners regarding the use of such supplements.

\section{Integrative nutrition}

Current clinical assessment guidelines in veterinary medicine stress the importance of a nutritional assessment, and conventional veterinary nutrition is a core component of the veterinary curriculum (Baldwin 
et al., 2010). However, the increase in the diversity of nutritional products, especially those marketed toward small animal owners, and in feeding strategies warrants specific consideration of these trends in the curriculum (Shmalberg, 2013a). Owners and veterinarians interested in IVM anecdotally appear more likely to adopt or recommend unconventional feeding practices. An IVM course would be uniquely positioned to discuss current knowledge and controversies in raw diets, home-prepared diets, grain-free diets, and feline nutrition (Hewson-Hughes et al., 2011; Zoran and Buffington, 2011; Verbrugghe et al., 2012; Freeman et al., 2013; Shmalberg, 2013b; Laflamme et al., 2014). The concept of natural diets and the impact of new pet food formulations should be reviewed (Buff et al., 2014). The course should also reinforce appropriate nutritional comparisons using the caloric basis method as compared to the guaranteed analysis or dry matter conversions (National Research Council Subcommittee on Dog and Cat Nutrition, 2006).

Nutritional assessment and intervention occurs in combination with other IVM modalities such as physical rehabilitation and sports medicine. Dietary modification can improve performance, preserve lean body mass, reduce inflammation, and improve recovery from injury (Shmalberg, 2014c, 2014d; Wakshlag and Shmalberg, 2014). Animals presenting for physical rehabilitation are frequently overweight or obese, and therefore a review of physiologic implications and current guidelines for the management of obesity would be appropriate in the course structure (Roudebush et al., 2008; Zoran, 2010; Michel, 2012; Brooks et al., 2014; Shmalberg and Memon, 2015). The relationship of nutrition to other traditional systems could be discussed; for example, TCVM stresses incorporation of food therapy, a concept of the energetic nature of diets applied by some CAVM practitioners to dietary recommendations. These concepts when incorporated without deference to conventional nutrient recommendations can produce clinically relevant deficiencies, and concepts of food energetics are not related to the measured concentrations of essential nutrients (Shmalberg, 2013b; Shmalberg, 2013c). Nevertheless, owners may raise the concept with veterinarians, who should be aware of the system and be able to respond using available evidence. Clinical examples of cases, which were presented with unconventional feeding practices or with prescribed integrative veterinary nutritional protocols, should be presented to reinforce critical concepts.

\section{Physical rehabilitation}

Physical rehabilitation and sports medicine of horses and dogs has received considerable attention in the last decade given the increased participation of animals in competitive pursuits and in the demand from veterinary clients for accelerated and complete recovery after an animal's injury. The newly approved American College of Veterinary Sports Medicine and Rehabilitation (ACVSMR) has increased the academic credibility of this discipline. Several comprehensive reviews and texts document the current knowledge in this emerging field (Buchner and Schildboeck, 2006; Hinchcliff et al., 2013; Millis and Levine, 2014; Zink and Van Dyke, 2013). Functional anatomy should be reviewed in the context of clinical cases, which establishes a clinical corollary to students' initial training in this area and a foundation to discuss condition-specific physical rehabilitation. Medical students appear to prefer such case-based exercises (Fajt et al., 2009; Thistlethwaite et al., 2012). The course should review soft tissue pathology as it relates to performance and rehabilitation, given that surgical courses may not focus on musculotendinous pathology. Conditions such as gracilis myopathy and medial shoulder instability would be examples of relevant canine conditions, as would superficial digital flexor tendinopathy and thoracolumbar pain in horses (Steiss, 2002; Wennerstrand et al., 2004; Parkin, 2008; Henderson et al., 2015). Instruction and demonstration of a comprehensive physical examination inclusive of soft tissue assessment, joint mobility, and dynamic lameness evaluation should be provided.

Rehabilitation practitioners frequently utilize a number of assistive modalities, the evidence for which should be discussed in the course. Underwater treadmill therapy is frequently employed in both species for rehabilitation and conditioning, with varying levels of evidence for this intervention depending on the condition treated (Jackson et al., 2002; Chauvet et al., 2011; King et al., 2013; Mooij et al., 2013). Photobiomodulation, or laser therapy, provides photonic stimulation of mitochondrial cytochromes thereby enhancing cellular energy production, upregulating antioxidant production, and releasing nitric oxide (Chung et al., 2012). Controversies regarding the dose and penetrance of photonic therapy in veterinary species persist, but a clinical study of dogs with intervertebral disc disease suggested possible benefits. Hyperbaric oxygen exerts similar effects as laser, and evidence for its reported uses in veterinary medicine are variable (Kerwin et al., 1993,2000; Ryan and Smith, 2007; Holder et al., 2008; Thom, 2011; Dhar et al., 2012; Draper et al., 2012; Shmalberg et al., 2015). Therapeutic ultrasound provides deep thermal heating of tissues to facilitate improved range of motion and may provide positive effects on collagen organization and strength in damaged tendons (Saini et al., 2002; Loonam et al., 2003). Shockwave therapy utilizes acoustic waves to cause mechanical effects in tissue, which have been purported to affect inflammation and endogenous healing, and the modality has been used in a number of conditions in dogs and horses (Dahlberg et al., 2005, 2006; Frisbie et al., 2009; Becker et al., 2015; Kieves 
et al., 2015). Specific therapeutic exercise protocols are developed for many patients, and the kinematic effects of such exercises are well described (Buchner et al., 1994; Buchner and Schildboeck, 2006; Millard et al., 2010; Drum et al., 2015). Such protocols could accelerate clinical improvement following injury, as documented for cranial cruciate ligament rupture in dogs (Monk et al., 2006). However, little evidence exists for many of the specific rehabilitative protocols advocated by some veterinarians. Students should learn to evaluate rehabilitation techniques critically.

\section{Conclusions}

IVM by definition requires constant refinement and should be guided by available scientific evidence. Consumer demand has accelerated the incorporation of many CAVM modalities into conventional practice. Consequently, students should receive adequate exposure to the principles, theories, and current knowledge supporting or refuting such techniques. These proposed curriculum guidelines would broadly introduce students to the objective evaluation of new veterinary treatments while increasing their preparation for responding to clinical questions about IVM in practice. Such a course should be evidence-based, unbiased, and unaffiliated with any particular CAVM advocacy or training group. Each institution should ensure compliance and consistency with their college's educational standards by performing periodic evaluation of integrative medicine courses. Student and graduate surveys provide one possible metric, but other authors recommend an objective faculty panel evaluation (Marcus and McCullough, 2009; Memon and Sprunger, 2011). IVM courses will likely need routine updating as new information becomes available, and institutions without faculty trained in these areas should consider recruitment of outside speakers to provide education in this area when it is not logistically and financially feasible to recruit permanent faculty in these areas. Controversies regarding IVM and CAVM should be addressed within the course and throughout the entire curriculum. Instructional honesty regarding the uncertainties in this emerging field is critical. Skeptics of integrative medicine in human health professions understand the need for training in this area, and one prominent skeptic related that "without additional education about alternative medicine, physicians cannot obtain accurate information from patients about their use of alternative modalities, or provide information and guidance." (Marcus, 2001). The authors hope that increased training of our future colleagues will demonstrate the openness to new ideas that characterizes the scientific method and a willingness to pursue and incorporate evidence-based medicine in clinical practice with all therapies, including those presently regarded as integrative, complementary, or alternative.

\section{Acknowledgements}

All authors are Diplomates of AVMA-recognized specialty colleges and are certified in at least one integrative veterinary medicine modality commonly used in the treatment of veterinary patients. These guidelines were authored during Dr. Memon's sabbatical as a visiting professor with the Integrative Medicine Service, College of Veterinary Medicine, University of Florida.

\section{Conflict of interest}

The authors declare that there is no conflict of interest.

\section{References}

AVMA Alternative and Complementary Therapies Task Force. 2001. An insight into the AVMA Guidelines for Complementary and Alternative Veterinary Medicine. J. Am. Vet. Med. Assoc. 218, 1729-1731.

Baldwin, K., Bartges, J., Buffington, T., Freeman, L.M., Grabow, M., Legred, J. and Jr., D.O. 2010. AAHA Nutritional Assessment Guidelines for Dogs and Cats. J. Am. Anim. Hosp. Assoc. 46, 285-296.

Becker, W., Kowaleski, M.P., McCarthy, R.J. and Blake, C.A. 2015. Extracorporeal Shockwave Therapy for Shoulder Lameness in Dogs. J. Am. Anim. Hosp. Assoc. 51, 15-19.

Benjamin, P.J., Phillips, R., Warren, D., Salveson, C., Hammerschlag, R., Snider, P., Haas, M., Barrett, R., Chapman, T. and Kaneko, R. 2007. Response to a proposal for an integrative medicine curriculum. J. Altern. Comp. Med. 13, 1021-1034.

Bergenstrahle, A.E. and Nielsen, B.D. 2015. Attitude and behavior of veterinarians surrounding the use of complementary and alternative veterinary medicine in the treatment of equine musculoskeletal pain. J. Eq. Vet. Sci. 35, 395.

Beyerstein, B.L. 2001. Alternative medicine and common errors of reasoning. Academic Med. 76, 230-237.

Brooks, D., Churchill, J., Fein, K., Linder, D., Michel, K.E., Tudor, K., Ward, E. and Witzel, A. 2014. 2014 AAHA Weight Management Guidelines for Dogs and Cats. J. Am. Anim. Hosp. Assoc. 50, 1-11.

Brown, D.C. and Reetz, J. 2012. Single agent polysaccharopeptide delays metastases and improves survival in naturally occurring hemangiosarcoma. J. Altern. Comp. Med. 2012, 1-8.

Buchner, H., Savelberg, H., Schamhardt, H., Merkens, H. and Barneveld, A. 1994. Kinematics of treadmill versus overground locomotion in horses. Vet. Q. 16(suppl. 2), S87-90.

Buchner, H.H.F. and Schildboeck, U. 2006. Physiotherapy applied to the horse: a review. Equine Vet. J. 38, 574-580.

Buff, P.R., Carter, R.A., Bauer, J.E. and Kersey, J.H. 2014. Natural pet food: A review of natural diets 
and their impact on canine and feline physiology. J. Anim. Sci. 92, 3781-3791.

Cantwell, S.L. 2010. Traditional Chinese Veterinary Medicine: The Mechanism and Management of Acupuncture for Chronic Pain. Top. Companion Anim. Med. 25, 53-58.

Chauvet, A., Laclair, J., Elliott, D.A. and German, A.J. 2011. Incorporation of exercise, using an underwater treadmill, and active client education into a weight management program for obese dogs. Can. Vet. J. 52, 491-496.

Chung, H., Dai, T., Sharma, S., Huang, Y.-Y., Carroll, J. and Hamblin, M. 2012. The Nuts and Bolts of Lowlevel Laser (Light) Therapy. Ann. Biomed. Eng. 40, 516-533.

Corti, L. 2014. Massage Therapy for Dogs and Cats. Top. Companion Anim. Med. 29, 54-57.

Dahlberg, J., Fitch, G., Evans, R., McClure, S. and Conzemius, M. 2005. The evaluation of extracorporeal shockwave therapy in naturally occurring osteoarthritis of the stifle joint in dogs. Vet. Comp. Orthop. Traumatol. 18, 147-152.

Dahlberg, J.A., McClure, S.R., Evans, R.B. and Reinertson, E.L. 2006. Force platform evaluation of lameness severity following extracorporeal shock wave therapy in horses with unilateral forelimb lameness. J. Am. Vet. Med. Assoc. 229, 100-103.

Debelle, F.D., Vanherweghem, J.L. and Nortier, J.L. 2008. Aristolochic acid nephropathy: a worldwide problem. Kidney Int. 74, 158-169.

Dhar, M., Neilsen, N., Beatty, K., Eaker, S., Adair, H. and Geiser, D. 2012. Equine peripheral blood-derived mesenchymal stem cells: Isolation, identification, trilineage differentiation and effect of hyperbaric oxygen treatment. Equine Vet. J. 44, 600-605.

Draper, W.E., Schubert, T.A., Clemmons, R.M. and Miles, S.A. 2012. Low-level laser therapy reduces time to ambulation in dogs after hemilaminectomy: a preliminary study. J. Small Anim. Pract. 53, 465-469.

Drum, M.G., Marcellin-Little, D.J. and Davis, M.S. 2015. Principles and Applications of Therapeutic Exercises for Small Animals. Vet. Clin. North Am. Small Anim. Pract. 45, 73-90.

Ernst, E. 2006. Acupuncture--a critical analysis. J. Intern. Med. 259, 125-137.

Ernst, E. 2011. How much of CAM is based on research evidence? Evid. Based Complement Alternate. Med. 2011:67649. http://dx.doi.org/10.1093/ecam/nep044

Evans, R. 2009. Evidence-based orthopaedics or 'superstition in the pigeon'. Vet. Comp. Orthop. Traumatol. 22, 346-350.

Fajt, V.R., Brown, D. and Scott, M.M. 2009. Practicing the skills of evidence-based veterinary medicine through case-based pharmacology rounds. J. Vet. Med. Educ. 36, 186-195.
Filburn, C., Kettenacker, R. and Griffin, D. 2007. Bioavailability of a silybin-phosphatidylcholine complex in dogs. J. Vet. Pharmacol. Ther. 30, 132-138.

Frass, M., Strassl, R.P., Friehs, H., Müllner, M., Kundi, M. and Kaye, A.D. 2012. Use and acceptance of complementary and alternative medicine among the general population and medical personnel: A systematic review. Ochsner J. 12, 45-56.

Freeman, L.M., Chandler, M.L., Hamper, B.A. and Weeth, L.P. 2013. Current knowledge about the risks and benefits of raw meat-based diets for dogs and cats. J. Am. Vet. Med. Assoc. 243, 1549-1558.

Frenkel, M., Frye, A., Heliker, D., Finkle, T., Yzaguirre, D., Bulik, R. and Sierpina, V. 2007. Lessons learned from complementary and integrative medicine curriculum change in a medical school. Med. Educ. 41, 205-213.

Frisbie, D. D., Kawcak, C.E. and McIlwraith, C.W. 2009. Evaluation of the effect of extracorporeal shock wave treatment on experimentally induced osteoarthritis in middle carpal joints of horses. Am. J. Vet. Res. 70, 449-454.

Gaster, B., Unterborn, J.N., Scott, R.B. and Schneeweiss, R. 2007. What Should Students Learn about Complementary and Alternative Medicine? Acad. Med. 82, 934-938.

Grassie, L. 2002. Update on animal dietary supplements. FDA Vet. News 16, 3.

Groppetti, D., Pecile, A.M., Sacerdote, P., Bronzo, V. and Ravasio, G. 2011. Effectiveness of electroacupuncture analgesia compared with opioid administration in a dog model: a pilot study. Br. J. Anaesth. 107, 612-618.

Habacher, G., Pittler, M.H. and Ernst, E. 2006. Effectiveness of Acupuncture in Veterinary Medicine: Systematic Review. J. Vet. Intern. Med. 20, 480-488.

Harris, P., Cooper, K., Relton, C. and Thomas, K. 2012. Prevalence of complementary and alternative medicine (CAM) use by the general population: a systematic review and update. Intern. J. Clin. Pract. 66, 924-939.

Hartman, S.E. 2009. Why do ineffective treatments seem helpful? A brief review. Chiropr. Osteopat. 17, 10. http://doi.org/10.1186/1746-1340-17-10

Haussler, K.K. 2009. Review of Manual Therapy Techniques in Equine Practice. J. Equine Vet. Sci. 29, 849-869.

Haussler, K.K., Hill, A.E., Puttlitz, C.M. and McIlwraith, C.W. 2007. Effects of vertebral mobilization and manipulation on kinematics of the thoracolumbar region. Am. J. Vet. Res. 68, 508-516.

Hayashi, A.M., Matera, J.M. and de Campos Fonseca Pinto, A.C.B. 2007. Evaluation of electroacupuncture treatment for thoracolumbar 
intervertebral disk disease in dogs. J. Am. Vet. Med. Assoc. 231, 913-918.

Health, N.I.o. 2011. National Center for Complementary and Alternative Medicine Third Strategic Plan 20112015. In National Center for Complementary and Alternative Medicine Third Strategic Plan 20112015 Ed Services, D.o.H.a.H. pp: 62.

Henderson, A.L., Latimer, C. and Millis, D.L. 2015. Rehabilitation and Physical Therapy for Selected Orthopedic Conditions in Veterinary Patients. Vet. Clin. North Am. Small Anim. Prac. 45, 91-121.

Hewson-Hughes, A.K., Hewson-Hughes, V.L., Miller, A.T., Hall, S.R., Simpson, S.J. and Raubenheimer, D. 2011. Geometric analysis of macronutrient selection in the adult domestic cat, Felis catus. J. Exp. Biol. 214, 1039-1051.

Hill, C. and Crook, T. 2010. The relationship between massage to the equine caudal hindlimb muscles and hindlimb protraction. Equine Vet. J. 42, 683-687.

Hinchcliff, K.W., Kaneps, A.J. and Geor, R.J. 2013. Equine sports medicine and surgery. Elsevier Health Sciences. ISBN: 978-0-7020-4771-8.

Holder, T.E., Schumacher, J., Donnell, R.L., Rohrbach, B.W. and Adair, H.S.A. 2008. Effects of hyperbaric oxygen on full-thickness meshed sheet skin grafts applied to fresh and granulating wounds in horses. Am. J. Vet. Res. 69, 144-147.

Holmes, M.A. 2009. Philosophical foundations of evidence-based medicine for veterinary clinicians. J. Am. Vet. Med. Assoc. 235, 1035-1039.

Imrie, R., Ramey, D., Buell, P., Ernst, E. and Basser, S. 2001. Veterinary Acupuncture and Historical Scholarship: Claims for the Antiquity of Acupuncture. Sci. Rev. Alternat. Med. 5, 135-141.

Jackson, A., Millis, D., Stevens, M. and Barnett, S. 2002. Joint kinematics during underwater treadmill activity. Second International Symposium on Rehabilitation and Physical Therapy in Veterinary Medicine 1, 191.

Jarrett, R.H., Norman, E.J. and Squires, R.A. 2005. Liquorice and canine Addison's disease. N. Z. Vet. J. 53, 214.

Joaquim, J.G.F., Luna, S.P.L., Brondani, J.T., Torelli, S.R., Rahal, S.C. and de Paula Freitas, F. 2010. Comparison of decompressive surgery, electroacupuncture, and decompressive surgery followed by electroacupuncture for the treatment of dogs with intervertebral disk disease with long-standing severe neurologic deficits. J. Am. Vet. Med. Assoc. 236, 1225-1229.

Kapatkin, A.S., Tomasic, M., Beech, J., Meadows, C., Boston, R.C., Mayhew, P.D., Powers, M.Y. and Smith, G.K. 2006. Effects of electrostimulated acupuncture on ground reaction forces and pain scores in dogs with chronic elbow joint arthritis. J. Am. Vet. Med. Assoc. 228, 1350-1354.
Kerwin, S.C., Hosgood, G., Strain, G.M., Vice, C.C., White, C.E. and Hill, R.K. 1993. The Effect of Hyperbaric Oxygen Treatment on a Compromised Axial Pattern Flap in the Cat. Vet. Surg. 22, 31-36.

Kerwin, S.C., Lewis, D.D., Elkins, A.D., Oliver, J.L., Hosgood, G., Pechman, R.D., Dial, S.L. and Strain, G.M. 2000. Effect of hyperbaric oxygen treatment on incorporation of an autogenous cancellous bone graft in a nonunion diaphyseal ulnar defect in cats. Am. J. Vet. Res. 61, 691-698.

Kieves, N., MacKay, C., Adducci, K., Rao, S., Goh, C., Palmer, R. and Duerr, F. 2015. High energy focused shock wave therapy accelerates bone healing. Vet. Comp. Orthop. Traumatol. 28, 425-432.

King, M.R., Haussler, K.K., Kawcak, C.E., McIlwraith, C.W. and Reiser, R.F. 2013. Mechanisms of aquatic therapy and its potential use in managing equine osteoarthritis. Equine Vet. Educ. 25, 204-209.

Kligler, B., Maizes, V., Schachter, S., Park, C.M., Gaudet, T., Benn, R., Lee, R. and Remen, R.N. 2004. Core competencies in integrative medicine for medical school curricula: a proposal. Acad. Med. 79, 521-531.

Koh, R.B., Isaza, N., Xie, H., Cooke, K. and Robertson, S.A. 2014. Effects of maropitant, acepromazine, and electroacupuncture on vomiting associated with administration of morphine in dogs. J. Am. Vet. Med. Assoc. 244, 820-829.

Laflamme, D., Izquierdo, O., Eirmann, L. and Binder, S. 2014. Myths and Misperceptions About Ingredients Used in Commercial Pet Foods. Vet. Clin. North Am. Small Anim. Prac. 44, 689-698.

Lana, S.E., Kogan, L.R., Crump, K.A., Graham, J.T. and Robinson, N.G. 2006. The use of complementary and alternative therapies in dogs and cats with cancer. J. Am. Anim. Hosp. Assoc. 42, 361-365.

Lane, D.M. and Hill, S.A. 2016. Pressure algometry measurement of canine muscular pain near the thoracolumbar junction: evaluation of a modified technique. Vet. Anaesth. Analg. 43, 227-234.

Loonam, J., Millis, D. and Stevens, M. 2003. The effect of therapeutic ultrasound on tendon heating and extensibility. In The effect of therapeutic ultrasound on tendon heating and extensibility, Steamboat Springs, CO.

Makino, T., Okajima, K., Uebayashi, R., Ohtake, N., Inoue, K. and Mizukami, H. 2012. 3-Monoglucuronyl-glycyrrhretinic acid is a substrate of organic anion transporters expressed in tubular epithelial cells and plays important roles in licorice-induced pseudoaldosteronism by inhibiting 11beta-hydroxysteroid dehydrogenase 2 . J. Pharmacol. Exp. Ther. 342, 297-304.

Marcus, D.M. 2001. How should alternative medicine be taught to medical students and physicians? Acad. Med. 76, 224-229. 
Marcus, D.M. and McCullough, L. 2009. An Evaluation of the Evidence in "Evidence-Based" Integrative Medicine Programs. Acad. Med. 84, 1229-1234.

Mathie, R.T. and Clausen, J. 2015. Veterinary homeopathy: meta-analysis of randomised placebocontrolled trials. Homeopathy 104, 3-8.

McKenzie, B.A. 2012. Is complementary and alternative medicine compatible with evidencebased medicine? J. Am. Vet. Med. Assoc. 241, 421-426.

McMillan, F.D. 1999. The placebo effect in animals. J. Am. Vet. Med. Assoc. 215, 992-999.

Memon, M.A. and Sprunger, L.K. 2011. Survey of colleges and schools of veterinary medicine regarding education in complementary and alternative veterinary medicine. J. Am. Vet. Med. Assoc. 239, 619-623.

Michel, K.E. 2012. Nutritional management of body weight. In Nutritional management of body weight Eds Fascetti, A.J. and Delaney, S.J. John Wiley and Sons, West Sussex, UK. pp: 109-124.

Millard, R., Headrick, J. and Millis, D.L. 2010. Kinematic analysis of the pelvic limbs of healthy dogs during stair and decline slope walking. J. Smal Anim. Prac. 51, 419-422.

Millis, D. and Levine, D. 2014 . Canine Rehabilitation and Physical Therapy, $2^{\text {nd }}$ ed., Elsevier Saunders, St. Louis, MO, USA. ISBN: 9781437703092.

Monk, M.L., Preston, C.A. and McGowan, C.M. 2006. Effects of early intensive postoperative physiotherapy on limb function after tibial plateau leveling osteotomy in dogs with deficiency of the cranial cruciate ligament. Am. J. Vet. Res. 67, 529-536.

Mooij, M.J.W., Jans, W., den Heijer, G.J.L., de Pater, M. and Back, W. 2013. Biomechanical responses of the back of riding horses to water treadmill exercise. Vet. J. 198(Suppl. 1), e120-e123.

Muñana, K., Zhang, D. and Patterson, E. 2010. Placebo effect in canine epilepsy trials. J. Vet. Int. Med. 24, 166-170.

National Research Council Subcommittee on Dog and Cat Nutrition. 2006. Nutrient Requirements of Dogs and Cats. National Acad. Press, Washington DC.

Owens, B. 2015. 2015 Nobel Prize goes to antiparasitic drug discoverers. Lancet 386, 1433.

Parkin, T.D.H. 2008. Epidemiology of Racetrack Injuries in Racehorses. Vet Clin. North Am. Equine Pract. 24, 1-19.

Raditic, D.M. and Bartges, J.W. 2014. Evidencebased Integrative Medicine in Clinical Veterinary Oncology. Vet. Clin. North Am. Small Anim. Pract. 44, 831-853.

Ramey, D.W. 2000. Do acupuncture points and meridians actually exist? Compend. Cont. Educ. Pract. Vet. 22, 1132-1136.
Ramey, D.W. and Buell, P.D. 2004. Acupuncture and 'traditional Chinese medicine' in the horse. Part 1: A historical overview. Equine Vet. Educ. 16, 218-224.

Ramey, D.W., Lee, M.L. and Messer, N.T. 2001. A review of the Western language equine acupuncture literature. J. Equine Vet. Sci. 21, 56-60.

Rhind, S.M., Baillie, S., Brown, F., Hammick, M. and Dozier, M. 2008. Assessing competence in veterinary medical education: where's the evidence? J. Vet. Med. Educ. 35, 407-411.

Rhind, S.M., Baillie, S., Kinnison, T., Shaw, D.J., Bell, C.E., Mellanby, R.J., Hammond, J., Hudson, N.P., Whittington, R.E. and Donnelly, R. 2011. The transition into veterinary practice: opinions of recent graduates and final year students. BMC Med. Educ. 11, 64.

Robinson, N. 2006. The need for consistency and comparability of transitional acupuncture points across species. Am. J. Tr. Chin. Vet. Med. 1, 14-21.

Roudebush, P., Schoenherr, W.D. and Delaney, S.J. 2008. An evidence-based review of the use of therapeutic foods, owner education, exercise, and drugs for the management of obese and overweight pets. J. Am. Vet. Med. Assoc. 233, 717-725.

Ryan, T. and Smith, R. 2007. An investigation into the depth of penetration of low level laser therapy through the equine tendon in vivo. Ir. Vet. J. 60, 295-299.

Saini, N., Roy, K., Bansal, P., Singh, B. and Simran, P. 2002. A preliminary study on the effect of ultrasound therapy on the healing of surgically severed Achilles tendons in five dogs. J. Vet. Med. 49, 321-328.

Shmalberg, J. 2013a. A Comparison of the Nutrient Composition and Chinese Food Therapy Energetics of Common Canine and Feline Dietary Ingredients. Am. J. Tr. Chin. Vet. Med. 8.

Shmalberg, J. 2013b. Novel trends in small animal nutrition: a practical guide. Tod. Vet. Pract. 3, 38-45.

Shmalberg, J. 2013c. Nutritional secondary hyperparathyroidism and taurine deficiency in a dog fed a home-prepared diet during Chinese food therapy. Am. J. Tr. Chin. Vet. Med. 8, 69-72.

Shmalberg, J. 2014a. Acupuncture: History and Application. Clinicians Brief 59-61.

Shmalberg, J. 2014b. Addressing Rationale, Regulation and Adverse Effects of Feeding Supplements. Tod. Vet. Pract. 4, S1-2.

Shmalberg, J. 2014c. Part 1: Canine Performance Nutrition. Tod. Vet. Pract. 4, 72-76.

Shmalberg, J. 2014d. Part 2: Canine Rehabilitative Nutrition. Tod. Vet. Pract. 5, 87-90.

Shmalberg, J. 2015. Detection and quantification of neuroexcitatory alkaloids in modified Da Huo Luo Dan prescribed for paresis or paralysis in dogs. Am. J. Tr. Chin. Vet. Med. 10, 27-31. 
Shmalberg, J. and Burgess, J. 2014. A randomized controlled blinded clinical trial of electroacupuncture administered one month after cranial cruciate ligament repair in dogs. Am. J. Tr. Chin. Vet. Med. 9, 43-51.

Shmalberg, J., Davies, W., Lopez, S., Shmalberg, D. and Zilberschtein, J. 2015. Rectal temperature changes and oxygen toxicity in dogs treated in a monoplace chamber. Und. Hyperb. Med. 42, 95-102.

Shmalberg, J., Hill, R.C. and Scott, K.C. 2013. Nutrient and metal analyses of Chinese herbal products marketed for veterinary use. J. Anim. Physiol. Anim. Nutr. 97, 305-314.

Shmalberg, J. and Memon, M.A. 2015. A Retrospective Analysis of 5,195 Treatments in an Integrative Veterinary Medicine Service: Patient Characteristics, Presenting Complaints, and Therapeutic Interventions. Vet. Med. Int. http:// dx.doi.org/10.1155/2015/983621.

Sierpina, V.S. and Kreitzer, M.J. 2010. The continuing bias against complementary and integrative healthcare education. Explore (NY). 6, 54-56.

Steiss, J.E. 2002. Muscle disorders and rehabilitation in canine athletes. Vet. Clin. North Am. Small Anim. Pract. 32, 267-285.

Streeter, R.M. and Wakshlag, J.J. 2015. Nutritional support in hepatic failure in dogs and cats. Nutitional Management of Hospitalized Small Animals, WileyBlackwell, ISBN: 978-1-4443-3647-4. pp: 199-209.

Sullivan, K., Hill, A. and Haussler, K. 2008. The effects of chiropractic, massage and phenylbutazone on spinal mechanical nociceptive thresholds in horses without clinical signs. Equine Vet. J. 40, 14-20.

Thistlethwaite, J.E., Davies, D., Ekeocha, S., Kidd, J.M., MacDougall, C., Matthews, P., Purkis, J. and Clay, D. 2012. The effectiveness of case-based learning in health professional education. A BEME systematic review: BEME Guide No. 23. Med. Teacher 34, e421-e444.

Thom, S.R. 2011. Hyperbaric Oxygen: Its Mechanisms and Efficacy. Plast. Reconstr. Surg. 127, 131S-141S.

Ulett, G.A., Han, S. and Han, J.-s. 1998. Electroacupuncture: mechanisms and clinical application. Biol. Psychiatry 44, 129-138.

van der Kooy, F. and Sullivan, S.E. 2013. The complexity of medicinal plants: The traditional Artemisia annua formulation, current status and future perspectives. J. Ethnopharmacol. 150, 1-13.

Vandeweerd, J.M., Kirschvink, N., Clegg, P., Vandenput, S., Gustin, P. and Saegerman, C. 2012. Is evidence-based medicine so evident in veterinary research and practice? History, obstacles and perspectives. Vet. J. 191, 28-34.

Verbrugghe, A., Hesta, M., Daminet, S. and Janssens, G.P. 2012. Nutritional modulation of insulin resistance in the true carnivorous cat: a review. Crit. Rev. Food Sci. Nutr. 52, 172-182.

Vožeh, S. 2003. Is the increasing use of evidencebased pharmacotherapy causing the renaissance of complementary medicine? Br. J. Clin. Pharm. 56, 292-296.

Wakshlag, J. and Shmalberg, J. 2014. Nutrition for working and service dogs. Vet Clin. North Am. Small Anim. Pract. 44, 719-740.

Walji, R. and Boon, H. 2006. Redefining the randomized controlled trial in the context of acupuncture research. Complement Ther. Clin. Pract. 12, 91-96.

Wennerstrand, J., Johnston, C., RoethlisbergerHolm, K., Erichsen, C., Eksell, P. and Drevemo, S. 2004. Kinematic evaluation of the back in the sport horse with back pain. Equine Vet. J. 36, 707-711.

Wirth, K., Kow, K., Salute, M., Bacon, N. and Milner, R. 2014. In vitro effects of Yunnan Baiyao on canine hemangiosarcoma cell lines. Vet. Comp. Oncol. doi: 10.1111/vco.12100.

Wynn, S.G. and Fougere, B. 2006. Veterinary herbal medicine. Elsevier Health Sciences.

Xie, H. and Preast, V. 2004. Chinese Veterinary Herbal Handbook. Chi Institute of Chinese Medicine, Reddick, FL.

Xie, H. and Preast, V. 2013. Xie's veterinary acupuncture. John Wiley and Sons.

Zhang, R., Lao, L., Ren, K. and Berman, B.M. 2014. Mechanisms of acupuncture-electroacupuncture on persistent pain. Anesth. 120, 482-503.

Zink, M.C. and Van Dyke, J.B. 2013. Canine sports medicine and rehabilitation. John Wiley and Sons.

Zoran, D.L. 2010. Obesity in dogs and cats: a metabolic and endocrine disorder. Vet Clin. North Am. Small Anim. Pract. 40, 221-239.

Zoran, D.L. and Buffington, C.T. 2011. Effects of nutrition choices and lifestyle changes on the wellbeing of cats, a carnivore that has moved indoors. J. Am. Vet. Med. Assoc. 239, 596-606. 